\title{
GAMBARAN PENERAPAN NEUMAN SYSTEM MODEL PADA AGREGAT LANSIA DENGAN HIPERTENSI DI DESA WANAJAYA WILAYAH KERJA PUSKESMAS WANARAJA KABUPATEN GARUT
}

\author{
Rahmita Nuril Amalia ${ }^{1}$, Citra Windani, M. S $^{2}$
}

Instansi

\begin{abstract}
Asbtrak
Hipertensi merupakan penyakit yang timbul akibat pola dan gaya hidup modern dan banyak menyerang penduduk terutama diatas usia 40 tahun. Hipertensi di Kabupaten Garut tahun 2014, termasuk dalam 10 besar penyakit dengan jumlah kunjungan rawat jalan puskesmas sebanyak 111.601 kunjungan $(4,5 \%)$ dari keseluruhan jumlah penduduk. Tujuan penelitian ini adalah untuk mengetahui penerapan Neuman System Model pada agregat lansia dengan hipertensi di Desa Wanajaya wiiayah kerja Puskesmas Wanaraja Kabupaten Garut.

Penelitian ini merupakan penelitian kuantitatif deskriptif. Populasi dalam penelitian ini adalah lansia di Desa Wanajaya pada bulan November 2014. Pengambilan sampel dilakukan dengan cara cluster sampling, sehingga didapatkan 94 lansia yang tinggal di Desa Wanajaya wilayah kerja Puskesmas Wanaraja Kabupaten Garut. Hasil penerapan Neuman System Model dalam pengkajian agregat lansia dengan masalah hipertensi meliputi lima aspek yaitu aspek perkembangan, fisiologis, psikologis, sosial-kultural dan spiritual

Kesimpulan dari penelitian ini adalah Neuman System Model ini sangat memungkinkan untuk digunakan dalam pengkajian praktek keperawatan komunitas khususnya pada agregat lansia dengan masalah hipertensi, karena aspek pengkajiannya bersifat holistik yang meliputi pengkajian fisiologis, psikologis, sosial kultural, perkembangan, dan spiritual. Dalam intervensinya pun Neuman telah membagi intervensi dalam tiga tingkatan yaitu primer, sekunder, dan tersier dengan melihat tiga garis pertahanan yaitu flexible line defense, normal line defense, dan resisten line defense.
\end{abstract}

Kata kunci: Wanajaya, lansia, hipertensi, Neuman System Mode

\begin{abstract}
Hypertension ia a disease who caused by the pattern and style of modern life and attacking people, especially over the age of 40 years. Hypertension in Garut regency in 2014, including the top 10 diseases with the number of outpatient health clinic visits as many as 111601 visits (4.5\%) of the total population. The purpose of this study was to determine the application of the Neuman System Model in aggregate elderly with hypertension in the Wanajaya village, Wanaraja, Garut.

This study is descriptive quatitative research. The population in this study were elderly in Wanajaya village in November 2014. Sampling was done by cluster sampling, so we get 94 elderly people who live in Wanajaya village, Wanaraja, Garut.

The results of the application of the Neuman System Model in aggregate assessment of elderly with hypertension problems include five aspects: developmental, physiological, psychological, socio-cultural and spiritual.

The conclusion of this study is the Neuman Systems Model is very possible to be used in the assessment of community nursing practice, especially in the elderly aggregate with hypertension problems, because the review is holistic aspect which includes assessment of physiological, psychological, social, cultural, developmental, and spiritual. In any intervention intervention Neuman has been split into three levels, namely primary, secondary, and tertiary to see three lines of defense that is flexible line defense, the normal line defense, and the resistant line defense.
\end{abstract}

Keywords: Wanajaya, elderly, hypertension, Neuman Systems Model 


\section{PENDAHULUAN}

Perubahan pola dan gaya hidup modern menyebabkan penyakit jantung dan pembuluh darah banyak menyerang, terutama penduduk usia di atas 40 tahun. Salah satunya yaitu timbulnya penyakit darah tinggi atau yang sering disebut dengan hipertensi (Agrina, 2011). Hipertensi menjadi masalah pada usia lanjut karena sering ditemukan menjadi faktor utama payah jantung dan penyakit koroner. Lebih dari separuh kematian diatas usia 60 tahun disebabkan oleh penyakit jantung dan serebrovaskuler (Nugroho, 2009). Berdasarkan profil penduduk lansia tahun 2009, jenis keluhan yang paling banyak dialami oleh lansia adalah keluhan yang merupakan efek dari penyakit kronis seperti asam urat, hipertensi, rematik, darah rendah, dan diabetes yaitu 32,30\% ( Komisi Nasional Lanjut Usia, 2010).

Secara global penyakit kardiovaskuler menyebabkan 17 juta kematian pertahun. Dari jumlah tersebut 9,4 juta diantaranya disebabkan oleh komplikasi hipertensi. Pada tahun 2008, di seluruh dunia, sekitar $40 \%$ dari orang dewasa berusia 25 keatas telah didiagnosis hipertensi, jumlah ini meningkat dari 600 juta pada tahun 1980 menjadi 1 miliar pada tahun 2008. WHO memperkirakan jumlah penderita hipertensi akan terus meningkat seiring dengan peningkatan jumlah penduduk. Pada tahun 2025 mendatang, diperkirakan sekitar 29\% penduduk di dunia terkena hipertensi (WHO, 2013).

Prevalensi Hipertensi atau tekanan darah di Indonesia cukup tinggi yaitu mencapai angka 32\% dari seluruh populasi. Jumlah ini terus meningkat sesuai data WHO tahun 1995 jumlah penderita hipertensi di Indonesia hanya 12\% dari populasi, kemudian pada tahun 2008 meningkat menjadi 32\% (Depkes RI, 2012). Berdasarkan data RISKESDAS (2013), prevalensi hipertensi di Indonesia yang didapat pada usia $\geq 18$ tahun sebesar $25,8 \%$, tertinggi di Bangka Belitung (30,9\%), diikuti Kalimantan
Selatan $(30,8 \%)$, Kalimantan Timur $(29,6 \%)$ dan Jawa Barat (29,4\%). Prevalensi hipertensi di Indonesia yang didapat melalui kuesioner terdiagnosis tenaga kesehatan sebesar 9,4\%, yang didiagnosis tenaga kesehatan atau sedang minum obat sebesar $9,5 \%$. Jadi, ada $0,1 \%$ yang minum obat sendiri. Responden yang mempunyai tekanan darah normal tetapi sedang minum obat hipertensi sebesar $0.7 \%$. Jadi prevalensi hipertensi di Indonesia sebesar $26,5 \%(25,8 \%+0,7 \%)$.

Hipertensi di Kabupaten Garut berdasarkan data Dinas Kesehatan Kabupaten Garut tahun 2014 termasuk dalam 10 besar penyakit dengan jumlah kunjungan rawat jalan puskesmas sebanyak 111.601 kunjungan $(4,5 \%)$ dari keseluruhan jumlah penduduk.

Hipertensi akan berjalan terus menerus seumur hidup dalam tubuh seseorang dan sering tanpa disertai keluhan yang khas selama sebelum terjadi komplikasi pada organ tubuh. Bila tidak diatasi, hipertensi dapat menyebabkan jantung bekerja lebih keras sehingga menyebabkan serangan jantung, pembesaran jantung dan akhirnya gagal jantung. Hipertensi yang tidak segera ditangani juga dapat menyebabkan pecahnya pembuluh darah di otak yang dapat menjadi penyebab stroke, dapat juga menyebabkan gagal ginjal, kebutaan, dan gangguan kognitif. Hipertensi menyebabkan 45\% kematian akibat penyakit jantung dan 51\% kematian akibat penyakit stroke (WHO, 2013).

Hipertensi pada lansia dapat dikontrol guna mencegah komplikasi dengan cara memperbaiki sistem intrapersonal, interpersonal, dan ekstrapersonal dari lansia dengan pendekatan Neuman System Model. Fokus perhatian Neuman System Model adalah sistem respon klien aktual atau potensial pengaruh lingkungan dengan menggunakan prevensi perawatan primer, sekunder, dan tersier sebagai intervensi.

Neuman menggunakan pendekatan manusia dengan memasukkan konsep holistik, pendekatan 
sistem terbuka, dan konsep "stressor". meliputi aspek fisiologis, psikologis, sosiokultural, perkembangan dan spiritual yang berhubungan secara dinamis seiring dengan adanya responrespon sistem terhadap stressor baik dari lingkungan internal maupun eksternal.

Komponen utama dari model ini adalah adanya stress dan reaksi terhadap stress. Stressor lingkungan ini terdiri dari 3 tipe kekuatan intrapersonal, interpersonal, dan ekstrapersonal. Klien dipandang sebagai suatu sistem terbuka yang memiliki siklus input, proses, output dan feedback sebagai suatu pola organisasi yang dinamis. Dengan menggunakan perspektif sistem ini, maka kliennya bisa meliputi individu, kelompok, keluarga, komunitas atau kumpulan agregat lainnya dan dapat diterapkan oleh berbagai disiplin keilmuan.

Tujuan ideal dari model ini adalah untuk mencapai stabilitas sistem secara optimal. Apabila stabilitas tercapai maka akan terjadi revitalisasi dan sebagai sistem terbuka maka klien selalu berupaya untuk memperoleh, meningkatkan, dan mempertahankan keseimbangan diantara berbagai faktor, baik didalam maupun diluar sistem yang berupaya untuk mengusahakannya. Neuman menyebut gangguan-gangguan tersebut sebagai stressor yang memiliki dampak negatif atau positif. Reaksi terhadap stressor bisa potensial atau aktual melalui respon dan gejala yang dapat diidentifikasi.

Berdasarkan latar belakang diatas, maka dirasa perlu untuk menelaah pengkajian komunitas pada ageragat pada lansia dengan masalah hipertensi dengan menggunakan pendekatan Neuman System Model untuk pelaksanaan proses asuhan keperawatan yang dimulai dari pengkajian sampai evaluasi guna mewujudkan kesehatan lansia yang optimal.

Berdasarkan latar belakang masalah yang telah disampaikan diatas, maka rumusan masalah dari penelitian ini adalah bagaimana gambaran penerapan Neuman System Model pada pelaksanaan asuhan keperawatan pada agregat lansia dengan hipertensi di Desa Wanajaya wilayah kerja Puskesmas Wanaraja Kabupaten Garut.

Penelitian ini bertujuan untuk menggambarkan penerapan Neuman System Model pada pelaksanaan asuhan keperawatan pada agregat lansia dengan hipertensi di Desa Wanajaya wilayah kerja Puskesmas Wanaraja Kabupaten Garut.

\section{METODE PENELITIAN}

Penelitian ini dilaksanakan di Desa Wanajaya wilayah Kerja Puskesmas Wanaraja Kecamatan Wanaraja Kabupaten Garut pada bulan November 2014. Penelitian ini menggunakan metode kuantitatif deskriptif. Pengambilan sampel dilakukan dengan cara cluster sampling, dengan jumlah sampel sebanyak 94 lansia yang berusia antara 45-70 tahun yang tinggal di Desa Wanajaya wilayah kerja Puskesmas Wanaraja Kabupaten Garut.

Data yang dikumpulkan berupa data primer yang diperoleh dengan menggunakan alat yang berupa daftar pertanyaan yang diajukan kepada responden yaitu kuesioner dan wawancara dengan kader kesehatan dan tokoh masyarakat, serta analisis sumber data lansia pada bulan November 2014 di Desa Wanajaya wilayah kerja Puskesmas Wanaraja Kabupaten Garut.

Data yang diperoleh dikumpulkan melalui kuesioner yang diberikan kepada responden, pengisian kuesioner yang diisi sendiri oleh responden dan dibantu oleh kader di masingmasing RW. Pengumpulan data primer ini dilakukan pada bulan November 2014. Sebelum dilakukan pengambilan data, responden diberikan penjelasan mengenai maksud dan tujuan pengambilan data serta responden diberikan kesempatan untuk 
bertanya kepada peneliti jika ada pertanyaan yang kurang dimengerti atau kurang jelas.

Data yang diperoleh oleh peneliti, kemudian dilakukan analisis dengan menggunakan SPSS for Windows ver. 20.0. Analisis dilakukan dalam bentuk analisis univariat. Analisis univariat dilakukan untuk menghasilkan distribusi frekuensi dari variable independen dan variable dependen.

\section{HASIL PENELITIAN}

Hasil penelitian ini meliputi aspek perkembangan, fisiologis, psikologis, sosial, dan spiritual.

\section{Perkembangan}

a. Jenis Kelamin

Diagram pie di bawah menunjukkan proporsi jenis kelamin lansia yang berdasarkan pembagian kuesioner, yaitu sebanyak $85 \%$ jenis kelamin perempuan dan $15 \%$ jenis kelamin lakilaki.

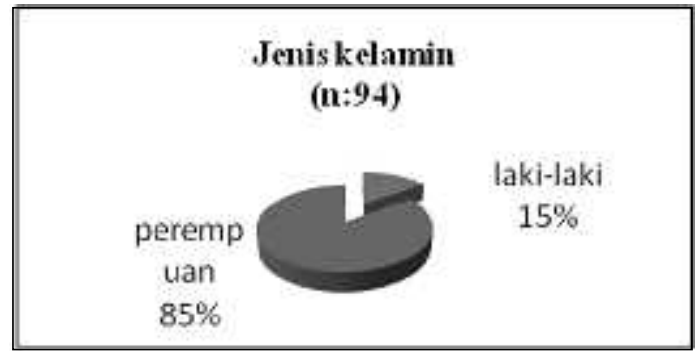

b. Usia

Diagram pie di bawah menunjukkan proporsi lansia berdasarkan usia, sebanyak $62 \%$ lansia memasuki masa pra lansia (45-59 tahun) dan sebanyak $38 \%$ lansia memasuki masa lansia pertengahan (60-70 tahun)

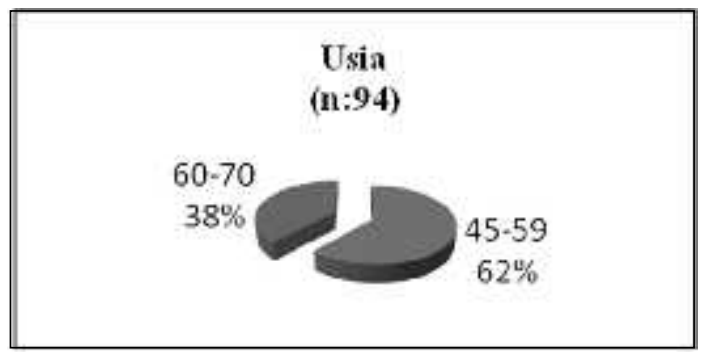

\section{c. Pengetahuan Lansia}

Diagram pie di bawah menunjukkan pengetahuan lansia mengenai hipertensi, sebanyak $41 \%$ lansia memiliki tingkat pengetahuan rendah, $37 \%$ lansia memiliki tingkat pengetahuan sedang, $22 \%$ lansia memiliki pengetahuan sedang tentang hipertensi. Hal ini terkait pengertian, penyebab, tanda dan gejala, pemeriksaan, batas normal tekanan darah, komplikasi, dan penatalaksanaan hipertensi.

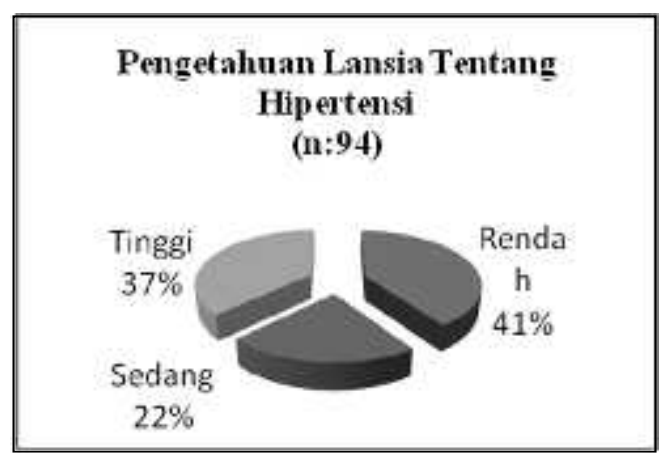

\section{d. Sikap Lansia}

Diagram pie dibawah menunjukkan sikap lansia terhadap hipertensi, bahwa sebanyak 59\% lansia memiliki sikap yang kurang baik dan $41 \%$ memiliki sikap yang baik terhadap hipertensi. Hal ini terkait dengan keinginan dan niat lansia dalam penanggulangan hipertensi.

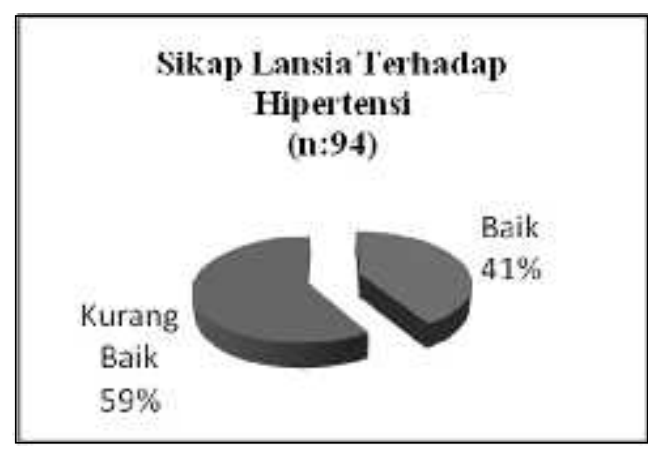

e. Perilaku Lansia

Diagram pie dibawah menunjukkan perilaku lansia yang berhubungan dengan hipertensi, sebanyak $60 \%$ lansia memiliki perilaku yang baik dan $40 \%$ lansia memiliki perilaku yang kurang baik. Hal ini terkait dengan kontrol tekanan darah, diet, aktivitas, dan konsumsi obat anti hipertensi. 


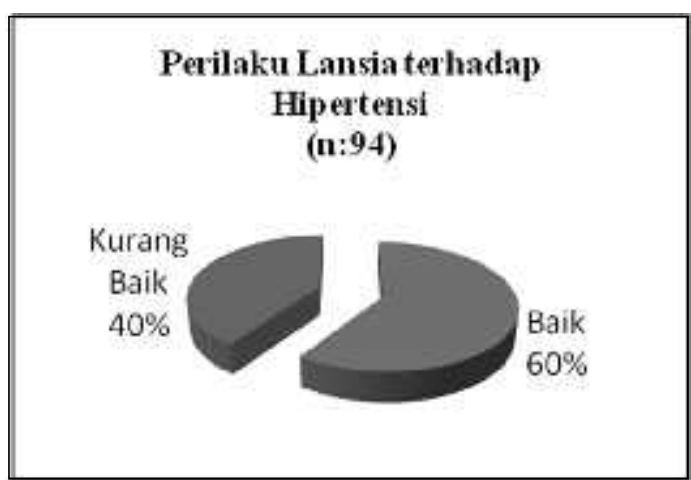

f. Penghasilan Lansia

Diagram pie di bawah menunjukkan sebanyak $68 \%$ lansia berpenghasilan kurang dari Rp. 800.000, 00 dan sebanyak 32\% lansia berpenghasilan lebih dari Rp. $800.000,00$

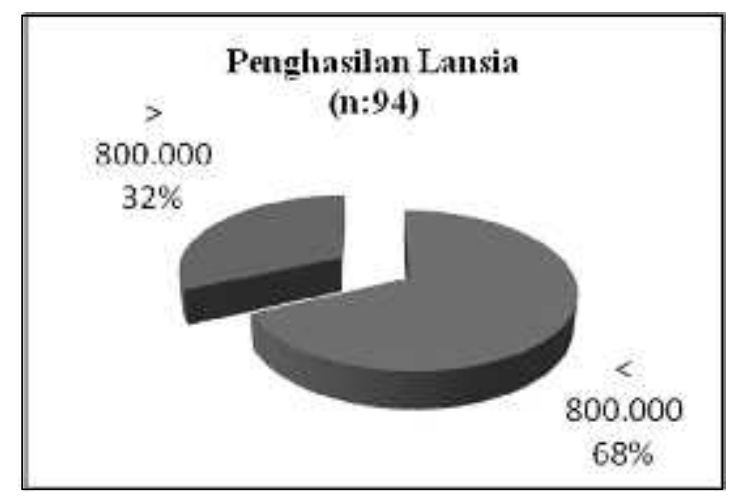

g. Dukungan Ekonomi Keluarga

Diagram pie di bawah menunjukkan 54\% keluarga memberikan dukungan ekonomi kepada lansia dan sebanyak $46 \%$ lansia tidak mendapatkan dukungan ekonomi dari keluarga

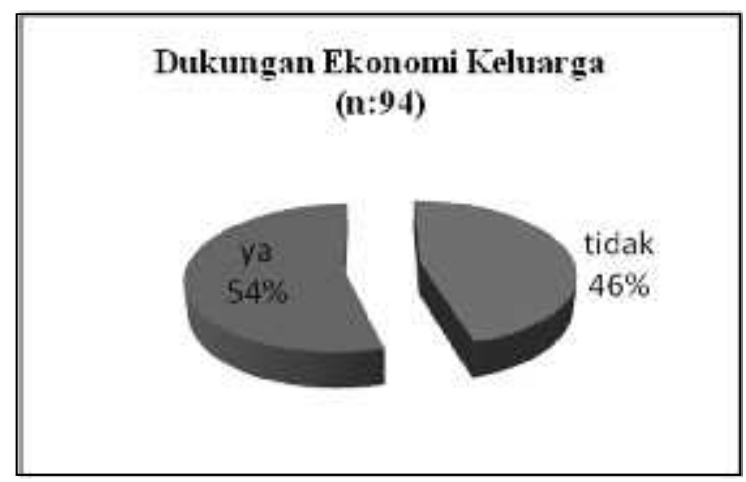

h. Riwayat Hipertensi pada Keluarga

Diagram pie di bawah menunjukkan riwayat penyakit hipertensi pada keluarga: $66 \%$ mengatakan ya (memiliki riwayat hipertensi pada keluarga), 34\% tidak memiliki riwayat hipertensi pada keluarga

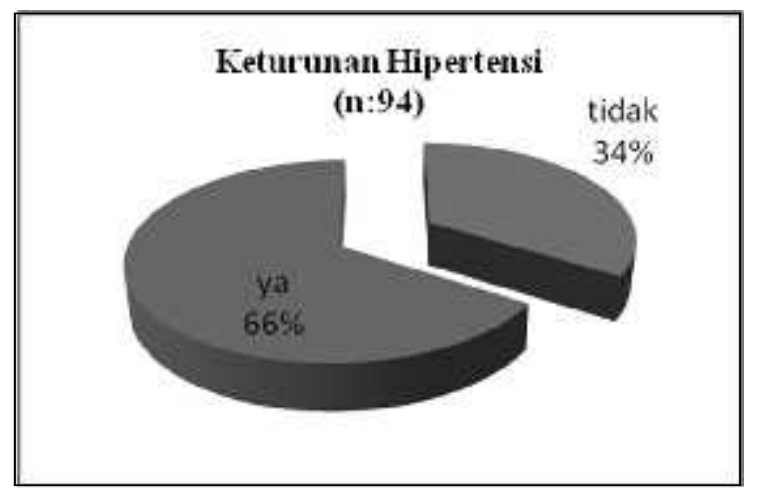

i. Dukungan Keluarga

Dalam hal dukungan keluarga: sebanyak

91\% lansia mendapatkan dukungan dari keluarga, dan sebanyak 9\% lansia tidak mendapatkan dukungan dari keluarga. Dukungan keluarga dalam bentuk perhatian sebanyak $64 \%$, dukungan dana sebanyak $21 \%$ dan $15 \%$ lansia mendapatkan dukungan keduanya (perhatian dan dana).

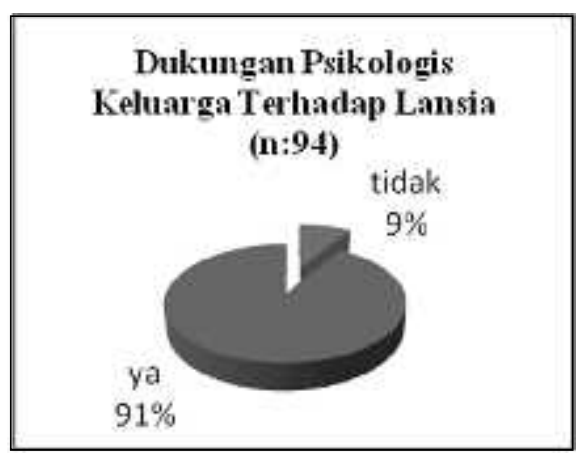

j. Aktivitas olahraga

Diagram pie dibawah menunjukkan aktivitas olahraga lansia, sebanyak $72 \%$ lansia mengatakan tidak rutin melakukan olah raga dan sebanyak $28 \%$ lansia melakukan olah raga secara rutin.

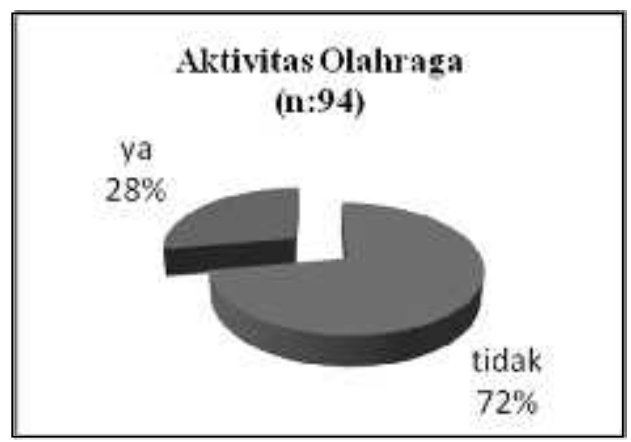




\section{Fisiologis}

a. Keluhan pusing yang dirasakan lansia

Diagram pie dibawah menunjukkan $90 \%$ lansia merasakan keluhan pusing dan $10 \%$ lansia tidak mengeluh pusing

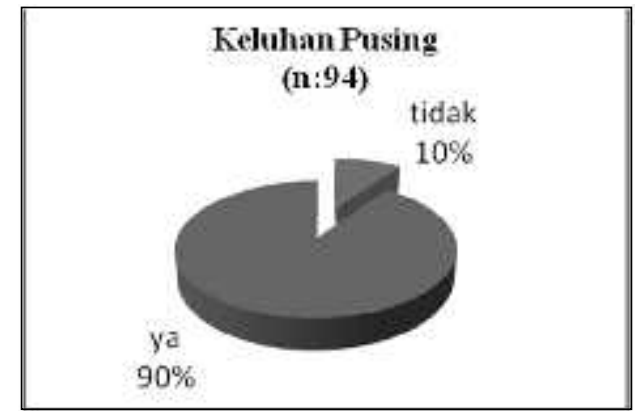

b. Keluhan kaku pada tengkuk pada lansia

Diagram pie dibawah menunjukkan $91 \%$ lansia mengeluh kaku pada tengkuk dan 9\% lansia tidak mengeluh kaku pada tengkuk

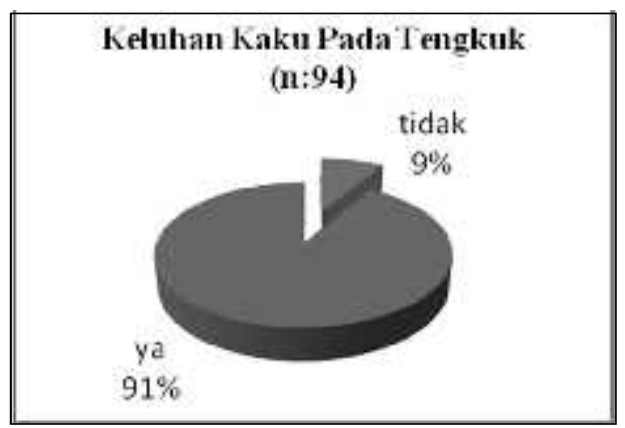

c. Tekanan darah lansia saat ini

Diagram pie dibawah ini menunjukkan derajat hipertensi lansia, sebanyak 35\% lansia mengalami hipertensi derajat I, 26\% lansia mengalami hipertensi derajat II, 21\% lansia mengalami hipertensi derajat III, dan $10 \%$ lansia memiliki tekanan darah normal.

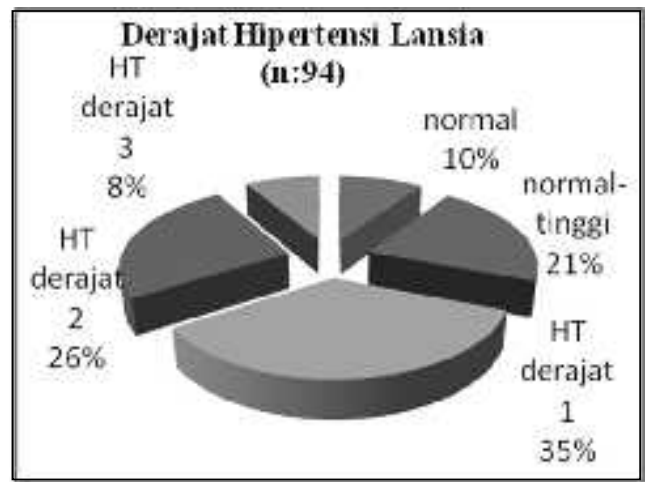

d. Kemandirian lansia

Diagram pie dibawah ini menunjukkan tingkat kemandirian lansia, sebanyak $63 \%$ lansia mandiri dan $37 \%$ lansia membutuhkan bantuan dalam melakukan aktivitas hidup sehari-hari

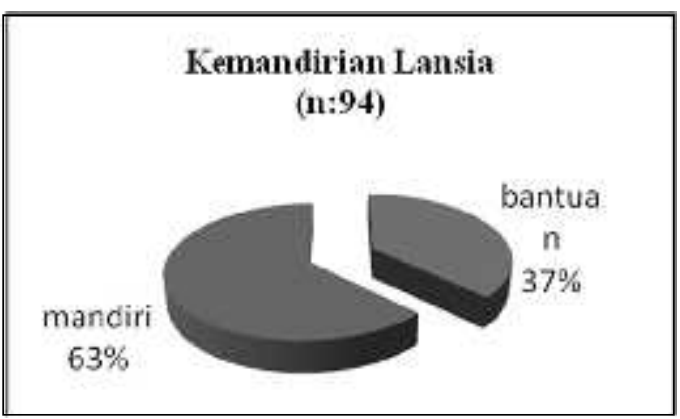

\section{Psikologis}

a. Koping lansia

Diagram pie di bawah ini menunjukkan koping individu lansia, sebanyak $62 \%$ lansia memiliki koping individu yang baik dan $38 \%$ lansia memiliki koping individu yang kurang baik. Koping individu lansia ini terdiri dari kecemasan lansia terhadap penyakit yang dialaminya $(90 \%$ cemas dan $10 \%$ tidak cemas), memikirkan masalah kesehatan $(79 \%$ lansia memikirkan kondisi kesehatannya dan $15 \%$ lansia tidak memikirkan kondisi kesehatannya), lansia menangis akibat masalah kesehatan yang dialaminya (52\% lansia tidak menangis dan $48 \%$ lansia menangis), penerimaan kondisi kesehatan lansia $(81 \%$ lansia menerima kondisi dan $19 \%$ lansia tidak dapat menerima kondisi kesehatannya), upaya penyelesaian masalah (64\% lansia berupaya untuk memperbaiki kesehatannya dan 36\% lansia belum berupaya memperbaiki kesehatannnya.

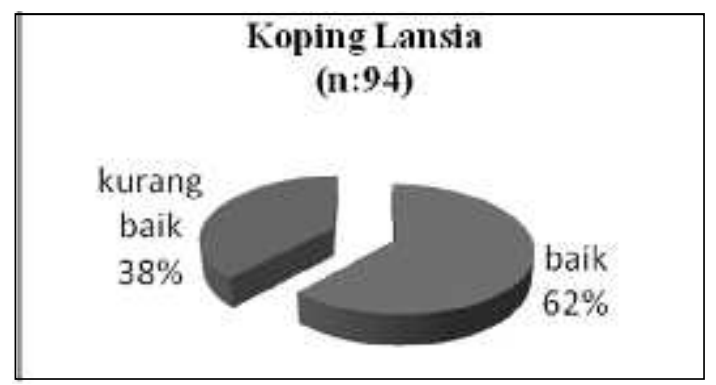




\section{b. Dukungan Lansia}

Diagram pie dibawah ini menunjukkan dukungan bagi lansia baik yaitu sebesar $84 \%$ dan $16 \%$ lansia memiliki dukungan yang kurang baik. Penilaian dukungan sosial lansia meliputi keberadaan peran lansia di masyarakat (78\% lansia mengatakan masih dibutuhkan di masyarakat dan 22\% lansia mengatakan tidak dibutuhkan di masyarakat), keberadaan keluarga dan tetangga yang dapat diandalkan oleh lansia $(81 \%$ lansia mengatakan memiliki tetangga dan keluarga yang dapat diandalkan dan 19\% mengatakan tidak memiliki keluarga maupun tetangga yang dapat diandalkan), dukungan keluarga terhadap masalah kesehatan lansia (91\% memiliki dukungan yang baik dari keluarga dan $9 \%$ memiliki dukungan yang kurang baik dari keluarga), wujud dukungan keluarga (64\% mendapat dukungan dana, 21\% mendapat dukungan dana, dan 15\% mendapat dukungan dana dan perhatian), keberadaan dukungan masyarakat terhadap masalah kesehatan lansia (71\% mendapat dukungan yang baik dari masyarakat dan $29 \%$ kurang mendapat dukungan yang baik dari masyarakat).

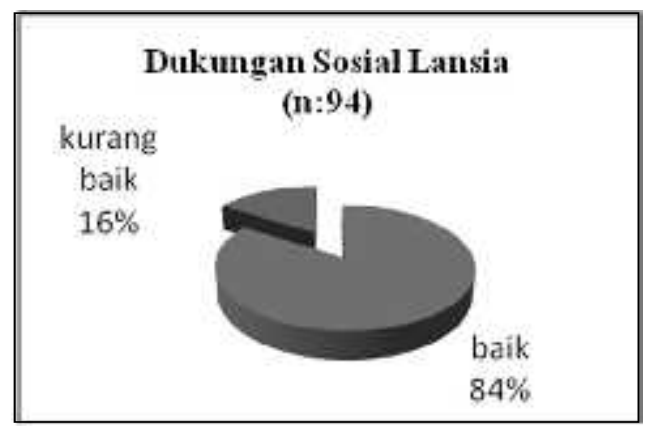

\section{Sosial Kultural}

a. Hubungan lansia dengan keluarga

Diagram pie di bawah ini menunjukkan hubungan keluarga dengan keluarga, sebanyak 92\% lansia memiliki hubungan yang harmonis dengan keluarganya, 5\% tidak harmonis, dan 3\% kurang harmonis.

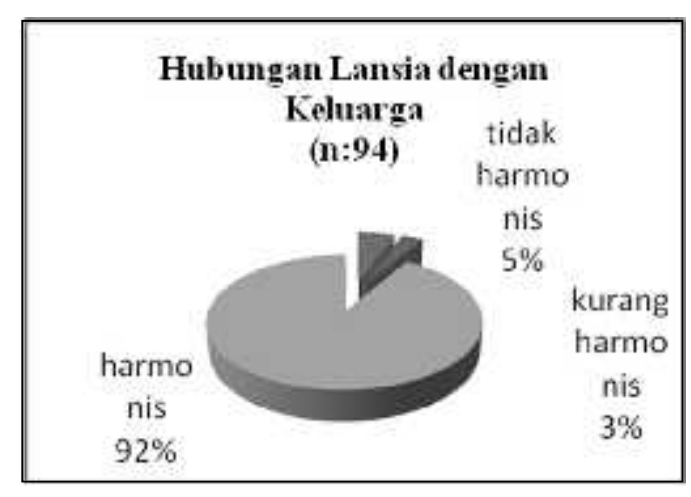

b. Hubungan lansia dengan tetangga sekitar tempat tinggal

Diagram pie di di bawah ini menunjukkan hubungan lansia dengan tetangga sekitar tempat tinggal, 98\% lansia memiliki hubungan yang harmonis, dan $2 \%$ memiliki hubungan yang kurang harmonis dengan tetangga sekitar tempat tinggal

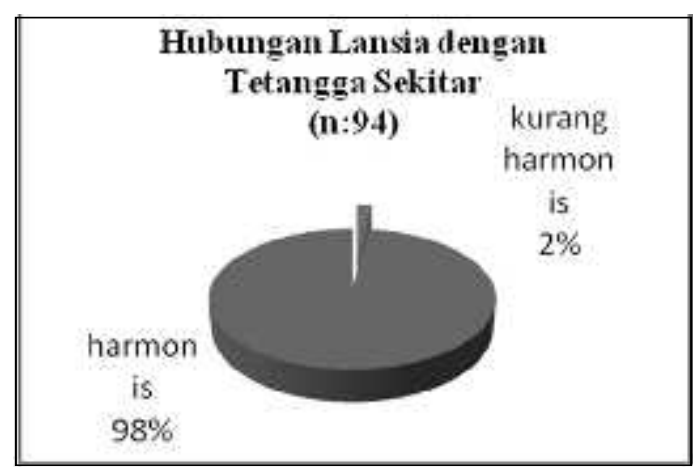

c. Keaktifan lansia dalam kegiatan masyarakat

Diagram pie di bawah ini menunjukkan bahwa $61 \%$ lansia tidak aktif ikut serta dalam kegiatan masyarakat dan 39\% lansia aktif serta dalam kegiatan masyarakat.

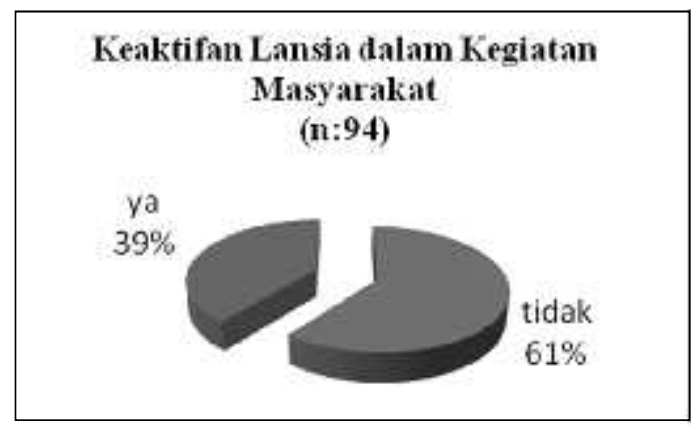

d. Kunjungan lansia ke Posbindu

Diagram di bawah ini menunjukkan 52\%

lansia aktif mengikuti posbindu dan $48 \%$ tidak aktif mengikuti kegiatan posbindu 


\section{Kunjungan Lansia ke Posbindu} (n:94)
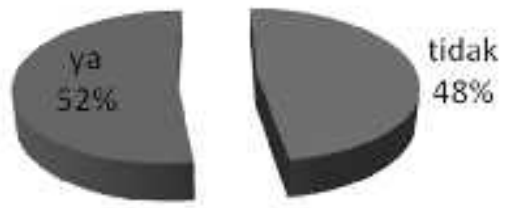

e. Pemanfaatan pelayanan kesehatan

Diagram pie di bawah ini menunjukkan bahwa $100 \%$ lansia pernah memanfaatkan pelayanan kesehatan jika terjadi masalah kesehatan

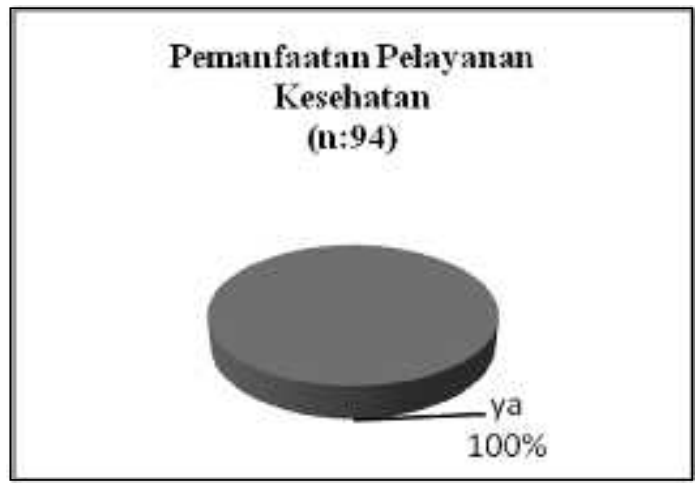

f. Jenis pelayanan kesehatan

Diagram pie di bawah ini menunjukkan

gambaran jenis pelayanan kesehatan yang dimanfaatkan oleh lansia jika mengalami masalah kesehatan. Sebanyak 68\% lansia memanfaatkan Puskesmas, 27\% lain-lain (lansia menyebutkan mantri dan bidan di daerah sekitar tempat tinggal), $4 \%$ memanfaatkan dokter praktek, dan $1 \%$ memanfaatkan Rumah Sakit.

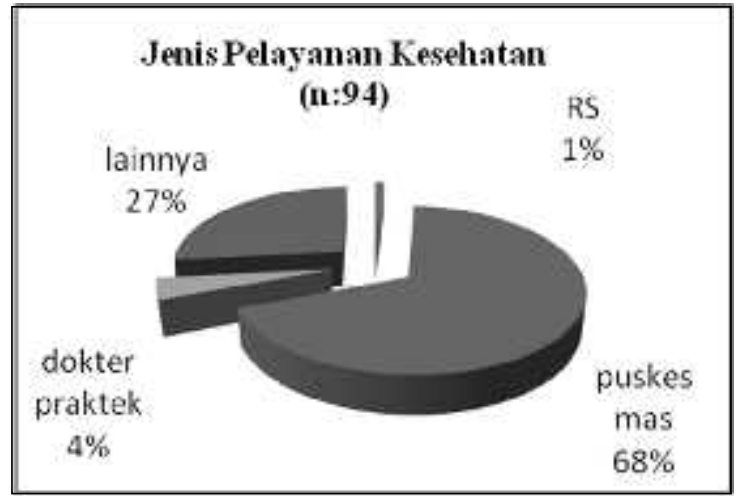

\section{g. Cakupan informasi mengenai hipertensi}

Diagram pie dibawah ini menunjukkan cakupan informasi yang didapat lansia mengenai hipertensi. $78 \%$ lansia mengatakan telah mendapatkan informasi mengenai hipertensi dan $22 \%$ mengatakan belum mendapatkan informasi mengenai hipertensi.

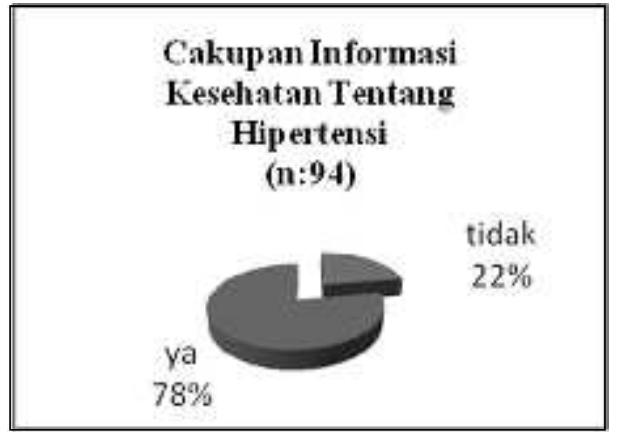

h. Sumber informasi

Diagram pie dibawah ini menunjukkan sumber informasi lansia tentang hipertensi. 62\% lansia memperoleh informasi tentang hipertensi dari petugas kesehatan, $22 \%$ belum mendapat informasi, 12\% lain-lain (lansia menyebutkan mantri dan bidan di daerah sekitar tempat tinggal), dan $4 \%$ dari media elektronik.

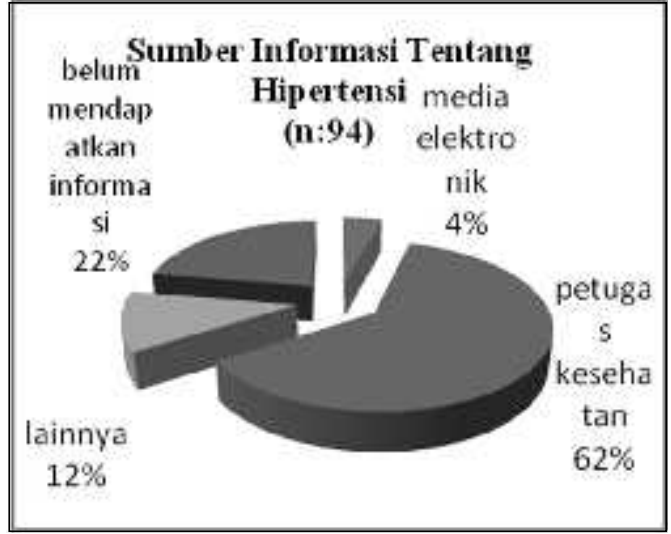

i. Budaya konsumsi makanan asin pada lansia

Diagram pie di bawah ini menunjukkan budaya mengkonsumsi yang dilakukan oleh lansia. $71 \%$ mengatakan tidak selalu mengkonsumsi makanan asin dan 29\% lansia mengatakan selalu mengkonsumsi makanan asin. 
Gambaran Penerapan Neuman System Model pada Agregat Lansia dengan Hipertensi di Desa Wanajaya Wilayah Kerja Puskesmas Wanaraja Kabupaten Garut

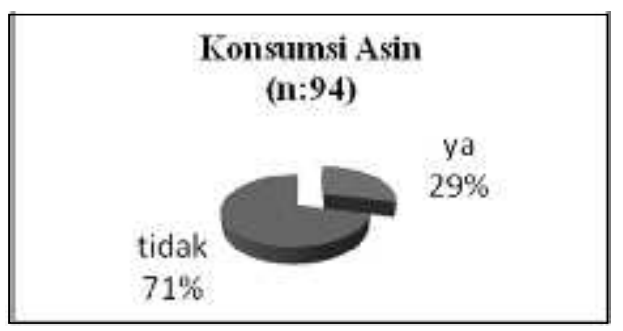

j. Budaya/keyakinan yang bertentangan dengan penanggulangan hipertensi

Diagram pie di bawah ini menunjukan budaya/keyakinan lansia yang bertentangan dengan penanggulangan hipertensi. $69 \%$ lansia mengatakan tidak memiliki budaya/keyakinan yang bertentangan dengan penanggulangan hipertensi dan $31 \%$ mengatakan memiliki keyakinan yang bertentangan dengan penanggulangan hipertensi.

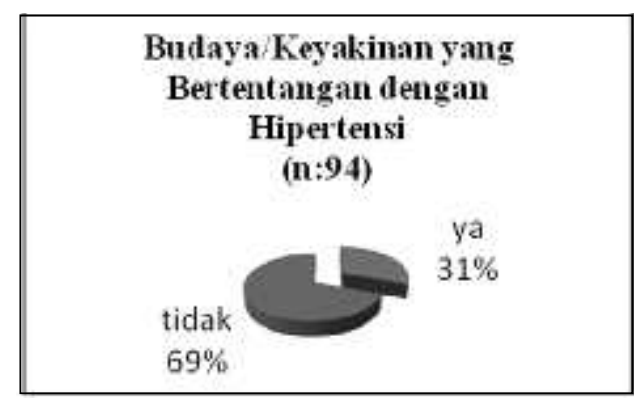

k. Kepercayaan lansia pada pengobatan tradisional

Diagram pie dibawah ini menunjukkan kepercayaan lansia pada pengobatan tradisional. $77 \%$ lansia mengatakan percaya pada pengobatan tradisional dan $23 \%$ mengatakan tidak percaya pada pengobatan tradisional.

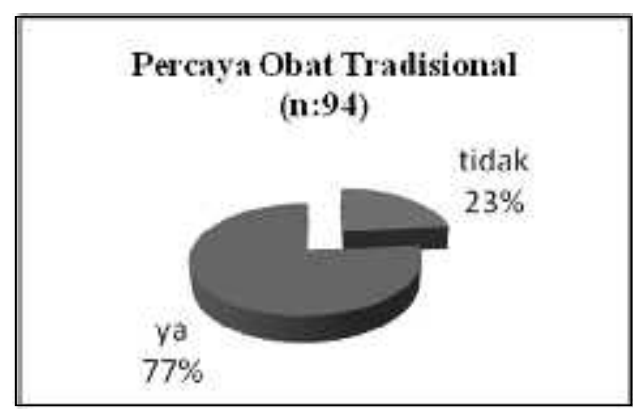

\section{Spiritual}

a. Agama yang dianut lansia

Diagram pie di bawah ini menunjukkan gambaran agama yang dianut oleh lansia. 100\% lansia di Desa Wanajaya menganut agama Islam

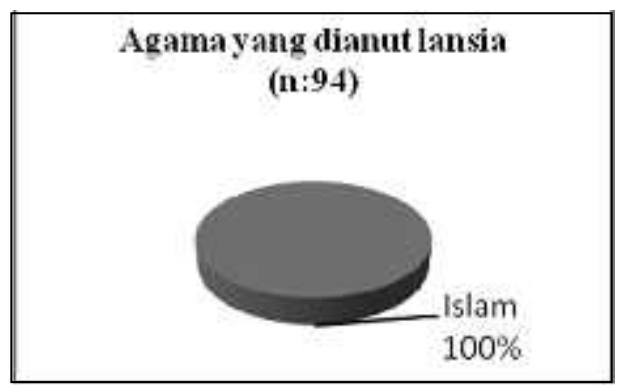

b. Rutinitas ibadah lansia

Diagram pie di bawah ini menunjukkan rutinitas ibadah lansia. 99\% lansia mengatakan rutin menjalankan ibadah sesuai ajaran agama Islam seperti sholat 5 waktu, $1 \%$ lansia mengatakan tidak rutin menjalankannya.

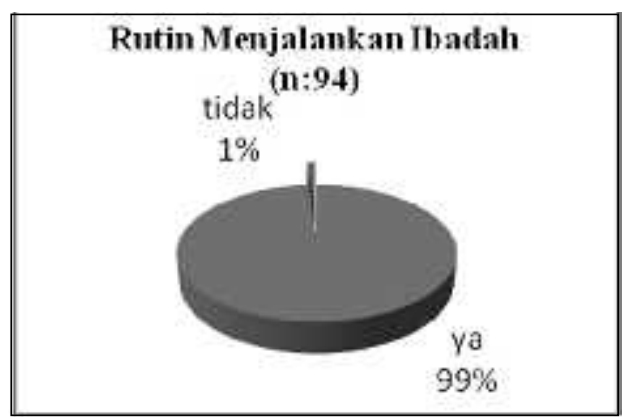

c. Partisipasi lansia dalam kegiatan keagamaan

Diagram pie di bawah ini menunjukkan partisipasi lansia dalam kegiatan keagamaan. 90\% lansia mengatakan selalu mengikuti kegiatan keagamaan yang diadakan di Desa Wanajaya, $10 \%$ mengatakan tidak aktif berpartisipasi dalam kegiatan keagamaan.

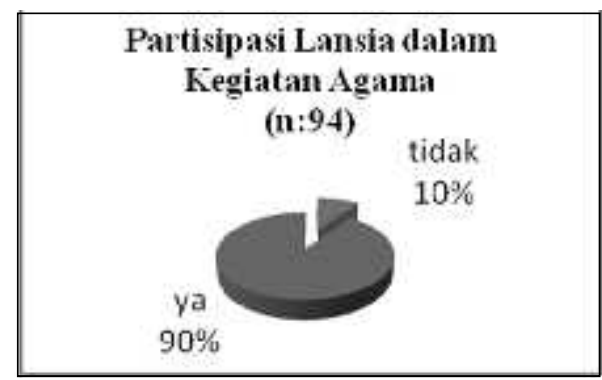


d. Perilaku berdoa sebagai upaya penyelesaian masalah

Diagram pie di bawah ini menunjukkan perilaku berdoa pada lansia sebagai salah satu upaya penyelesaian masalah. $72 \%$ lansia mengatakan selalu berdoa dan $28 \%$ lansia mengatakan tidak selalu menggunakan doa sebagai salah satu upaya penyelesaian masalah.

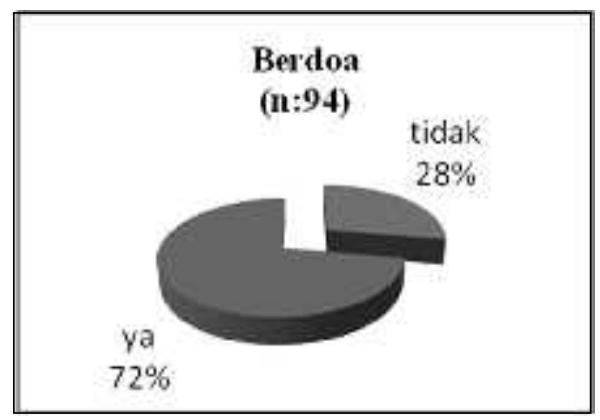

\section{PEMBAHASAN}

Lansia sebagai populasi beresiko (population at risk) mempunyai karakteristik usia, biologik dan usia, sosial, ekonomi, gaya hidup dan kejadian hidup. Faktor biologik yang terjadi pada lansia menyebabkan perubahan fungsi organ diantaranya jantung mengalami penebalan pada miokardial dan pembuluh darah terjadi kekakuan. Secara sosial lansia juga mengalami kehilangan peran dan produktivitas yang akan berdampak pada psikologis. Faktor ekonomi cenderung umum terjadi yaitu penurunan pendapatan dan gaya hidup lansia yang cenderung kurang berolah raga serta kurang memperhatikan diet. Selain itu lansia juga mengalami kehilangan orang yang dicintai yang dapat memperkuat timbulnya berbagai permasalahan kesehatan pada lansia (Stanhope \& Lancaster, 2004).

Peningkatan masalah kesehatan penting pada lansia karena lansia memiliki tingkat probabilitas yang tinggi terhadap penyakit daripada kelompok lain menyebabkan lansia juga termasuk dalam kelompok rentan atau vulnerable population (Stanhope \& Lancaster, 2004). Vulnerable population adalah kelompok yang memiliki kemungkinan dalam berkembangnya masalah kesehatan, lebih sulit untuk mengakses pelayanan kesehatan untuk menyelesaikan masalah kesehatan, kemungkinan besar penghasilannya kurang, atau masa hidup lebih singkat akibat kondisi kesehatan (Maurer \& Smith, 2005).

Betty Neuman berpendapat bahwa "Stressor mempengaruhi keseimbangan homeostatis jika keseimbangan ini terganggu maka energi dikeluarkan untuk mengatasinya”. Untuk membuat kehidupan menjadi seimbang, maka rangkaian sistem tersebut harus menjadi interaksi antara sesama manusia. Interaksi ini akan membuat seseorang meningkatkan ketahanan dalam kehidupannya. Dalam kehidupan sehari-hari individu selalu berusaha mempertahankan dan memenuhi kebutuhan biologi, psikologi dan sosial kultural. Adanya stress sebagai penyakit menyebabkan seseorang bereaksi untuk mempertahankan kesehatannya melalui mekanisme pemecahan masalah atau koping tertentu. Penyebab stressor dapat berasal dari diri sendiri, dari luar individu atau karena interaksi dengan orang lain, pada hubungan individu dengan stres, reaksinya atas stres, dan faktor-faktor pemulihan kembali yang dinamis secara alamiah. Pemulihan kembali (rekonstitusi) adalah kondisi adaptasi terhadap terhadap stressor.

Pada aspek perkembangan lansia, peneliti melihat seluruh hal yang berkaitan dengan perkembangan lansia yang meliputi usia, jenis kelamin, pengetahuan, sikap, dan perilaku lansia terhadap hipertensi, penghasilan lansia, dukungan ekonomi keluarga, riwayat hipertensi pada keluarga, dukungan psikologis pada keluarga, aktivitas olahraga lansia. Pada aspek ini, perilaku tidak berbanding lurus dengan pengetahuan dan sikap lansia terhadap hipertensi. Perilaku lansia yang baik dipengaruhi oleh berbagai macam 
faktor diantaranya adalah pola kebiasaan yang telah dilakukan lansia sejak dahulu, dan tidak selalu didasari oleh pengetahuan yang memadai khususnya tentang hipertensi.

Pada aspek fisiologis, peneliti melihat hal yang berkaitan dengan kondisi fisiologis lansia dengan masalah hipertensi. Sebagian besar lansia merasakan tanda dan gejala hipertensi yang paling umum seperti pusing dan kaku pada tengkuk. Sebanyak 35\% lansia mengalami hipertensi pada derajat I, 26\% lansia mengalami hipertensi derajat II, 21\% lansia mengalami hipertensi derajat III, dan $10 \%$ lansia memiliki tekanan darah normal. Tekanan darah pada lansia akan meningkat secara fisiologis seiring bertambahnya usia lansia, akan tetapi menurunkan tekanan darah lansia hingga pada 140/85-90 mmHg penting bagi lansia untuk mencegah komplikasi dari hipertensi.

Pada aspek psikologis, peneliti melihat koping dan dukungan lansia. Pada aspek ini peneliti mendapatkan koping dan dukungan yang cukup baik bagi lansia. Koping dan dukungan yang cukup baik sangat berperan penting bagi lansia dalam memperbaiki kesehatannya khususnya dalam upaya penanggulangan hipertensi. Kondisi psikologis yang baik dapat meningkatkan kesehatan fisik lansia.

Pada aspek sosial kultural, peneliti melihat hubungan sosial lansia dengan keluarga dan dengan tetangga sekitar, keaktifan lansia dalam kegiatan di masyarakat, kunjungan lansia ke posbindu, pemanfaatan pelayanan kesehatan, jenis pelayanan kesehatan, cakupan informasi mengenai hipertensi, sumber informasi, budaya konsumsi asin pada lansia, budaya yang bertentangan dengan upaya penanggulangan hipertensi, dan kepercayaan lansia terhadap obat tradisional. Pada aspek ini didapat hubungan sosial lansia cukup baik, akan tetapi lansia enggan untuk mengikuti kegiatan di masyarakat. Hal ini didukung dengan sebanyak $48 \%$ lansia tidak pernah melakukan kunjungan ke posbindu. Sebanyak 77\% lansia mempercayai pengobatan tradisional, hal ini perlu menjadi perhatian bagi pertugas kesehatan setempat untuk memantau konsumsi obat lansia agar sesuai dengan penanggulangan hipertensi dan tidak menimbulkan efek samping.

Aspek spiritual. Pada aspek ini peneliti melihat spiritual lansia cukup baik dibuktikan dengan sebanyak 99\% rutin melakukan ibadah, 90\% lansia aktif mengikuti kegiatan keagamaan, dan $72 \%$ lansia terbiasa berdoa sebagai salah satu upaya penyelesaian masalah. Spiritualitas yang baik pada lansia mampu memberikan ketenangan batin dalam menghadapai berbagai permasalahan yang ada. Kondisi spiritual lansia semakin membaik seriring bertambahnya usia lansia sesuai dengan tahap perkembangan lansia yang merupakan tahap akhir dari kehidupan manusia.

\section{KESIMPULAN}

Teori Betty Neuman ini sangat memungkinkan untuk digunakan dalam pengkajian praktek keperawatan komunitas khususnya pada agregat lansia dengan masalah hipertensi, karena aspek pengkajiannya bersifat holistik yang meliputi pengkajian fisiologis, psikologis, sosial kultural, perkembangan, dan spiritual. Dalam intervensinya pun Neuman telah membagi intervensi dalam tiga tingkatan yaitu primer, sekunder, dan tersier dengan melihat tiga garis pertahanan yaitu flexible line defense, normal line defense, dan resisten line defense.

\section{DAFTAR PUSTAKA}

1. Depkes RI. (2013). Masalah Hipertensi di Indonesia. Diakses dari http://depkes.go.id pada tanggal 15 Desember 2014.

2. Depkes RI. (2013). Riset Kesehatan Dasar. Jakarta: Badan Penelitian dan Pengembangan Kesehatan Kementrian Kesehatan RI 
Gambaran Penerapan Neuman System Model pada Agregat Lansia dengan Hipertensi di Desa Wanajaya Wilayah Kerja Puskesmas Wanaraja Kabupaten Garut

3. Komisi Nasional Lanjt Usia. (2010c). Profil 6. Neuman, B. (1990). Health as a continuum Penduduk Lanjut Usia. 2009. Jakarta: Komisi Nasional

Lanjut Usia

4. Komisi Nasiona Lanjut Usia. (2010b). Pedoman Pelaksanaan Posyandu Lanjut Usia. Jakarta: Komisi Nasional Lanjut Usia.

5. Nugroho, Wahyudi. (2008). Keperawatan Gerontik \& Geriatrik. Edisi ke 3. Jakarta: EGC based on the Neuman system's Model. Nursing Science

Quarterly, 3, 129-135

7. Stanhope, M., \& Lancaster, J. (2004).

Community and Public Health Nursing. St. Louis Missouri: Mosby.

8. WHO. (2013). A Global Briefon Hypertension: Silent Killer Global Public Health Crisis 